\title{
PORTABLE EQUIPMENT FOR INTENSIVE THERAPY
}

\author{
R. M. A. McClelland, M.B. (Lond.), F.F.A.R.C.S. \\ Senior Registrar, Nuffield Department of Anasthetics, Oxford \\ R. H. SALT, F.I.B.S.T. \\ Chief Technician, Nuffield Department of Ancesthetics, Oxford
}

Certain technical procedures, such as venepuncture, endotracheal intubation and artificial respiration are performed routinely by the anæsthetist. Additionally, he should be in the habit of making rapid assessment of the severely ill patient and instituting supportive therapy, particularly where there may be cardio-vascular or respiratory failure. As a natural consequence anæsthetists are no longer confined only to the anæsthetic room and operation theatre, but may be asked to help in the management of disease throughout hospital practice.

Respiratory obstruction, chest and head injuries, poliomyelitis and similar conditions, barbiturate intoxication, eclampsia, post-operative chest complications and intractable pain are all examples when a move is indicated from the conventional and limited sphere of pure anæsthesia, into the broader field of medicine in its widest sense.

\section{Problem}

This expanding role of the anæsthetist is leading to many problems. One is the difficulty to find enough time to see and supervise adequately patients who may be scattered in different wards of a large hospital. Another is that a wide range of equipment may be required at short notice, for cases of differing pathology.

The use of a recovery room has solved the problem concerning the immediate post-operative phase. Here all patients can be nursed together for the first few hours following surgery. And should an untoward incident occur, or extra care be required, then staff and apparatus are instantly available.

In America and Scandinavia this principle of concentration of staff and equipment has been extended to include the management of the severely-ill patients, and intensive-therapy units have been established for this purpose. Of the many obvious advantages of this system that of particular importance is the availability of apparatus, expert medical and highly-skilled nursing staff where they will be most valuable, instead of being dispersed throughout the hospital.

In Great Britain, at a few centres this ideal has been employed with the formation of special units where all cases of a similar nature are collected. For example, in Oxford, patients with poliomyelitis, polyneuritis, tetanus, myasthenia gravis and porphyria, who require tracheostomy and intermittent positive pressure respiration are nursed together in the Respiration Unit at the Churchill Hospital. But this only represents one aspect of the problem, respiratory failure; and unfortunately in this country where tradition, finance, and other matters play a dominant role, we are not able at present to offer the advantages of an intensive therapy unit to many patients.

However, there is no excuse for allowing a patient, who requires more than the average amount of care and attention, to lie almost unnoticed in the far corner of a ward. And to overcome some of the difficulties, with the concept of concentration in mind, we have made a portable unit for the emergency treatment of the severely ill.

In the past ten months the portable unit has been used on 23 occasions, and some details are included in Table $\mathbf{~}$.

\section{Description of Portable Intensive Therapy Unit}

The equipment, except an underwater seal drain, is housed in a ' Revelation' type of suitcase measuring $70 \times 45 \times 20 \mathrm{~cm}$., and of total weight $19 \mathrm{~kg}$.

Modifications to the suitcase include:

(I) A pair of $5 \mathrm{~cm}$. diameter wheels mounted by means of metal plates at one corner, and near the diametrically opposite corner an extra handle attached to the side. This allows the unit to be wheeled at an angle from one location to another. 
TABLE I

Uses in Chronological Order of the Portable Intensive Therapy Unit

\begin{tabular}{|c|c|c|c|}
\hline Occasion & Location & $\therefore \quad$ Patient's Condition & Remarks \\
\hline $\mathbf{I}$ & Casualty department & Barbiturate intoxication & Intubation and ventilation \\
\hline 2 & Ward & Fractured jaw & Bronchoscopy \\
\hline 3 & Ward & Post-operative chest complication & Toilet of chest \\
\hline 4 & Casualty department & Head injury & Pharyngeal toilet \\
\hline 5 & Ward & Head injury & Passage of stomach tube \\
\hline 6 & Ward & Cerebral abscess & Bronchoscopy, had inhaled food $;. . .:$ w \\
\hline 7 & Ward & Peptic ulceration, hæmatemesis & Bronchoscopy \\
\hline 8 & Ward & Fractured jaw & Intubation and toilet of chest \\
\hline 9 & Ward & Chest injury & Bronchoscopy \\
\hline 10 & Anæsthetic room & Chest injury & Relief of tension pneumothorax \\
\hline iI & Operating theatre & Chest injury & Relief of tension pneumothorax \\
\hline 12 & Ward & Esophageal varices, hæmatemesis & 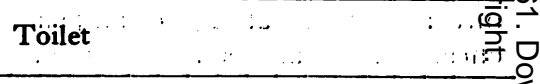 \\
\hline 13 & Ward & Head injury & Intubation and toilet of chest \\
\hline$\therefore \quad 14$ & X-Ray department & Cerebral tumour & $\begin{array}{l}\text { Cardiac massage following thiopentone } \\
\text { induction for angiogram }\end{array}$ \\
\hline 15 & Ward & Post-operative chest complication & Toilet of chest and I.V. therapy : \\
\hline 16 & Ward & Cerebral tumour & Toilet of chest \\
\hline 17 & Casualty department & Head injury & Passage of stomach tube \\
\hline 18 & Ward & Cerebral tumour & Bronchoscopy, inhaled food \\
\hline 19 & Ward & Head injury & $\begin{array}{c}\text { Intubation-respiratory obstruction due } \\
\text { to palatal odema after angiogram }\end{array}$ \\
\hline 20 & Ward & Post-operative chest complication & Toilet of chest and I.V. therapy \\
\hline$\therefore 21$ & Casualty department & Carbon monoxide poisoning & Intubation and ventilation \\
\hline 22 & Ward & Cor pulmonale & Change of tracheostomy tube \\
\hline 23 & Ward & Tetanus & Intubation, ventilation and curarization $\stackrel{\infty}{?}$ \\
\hline
\end{tabular}




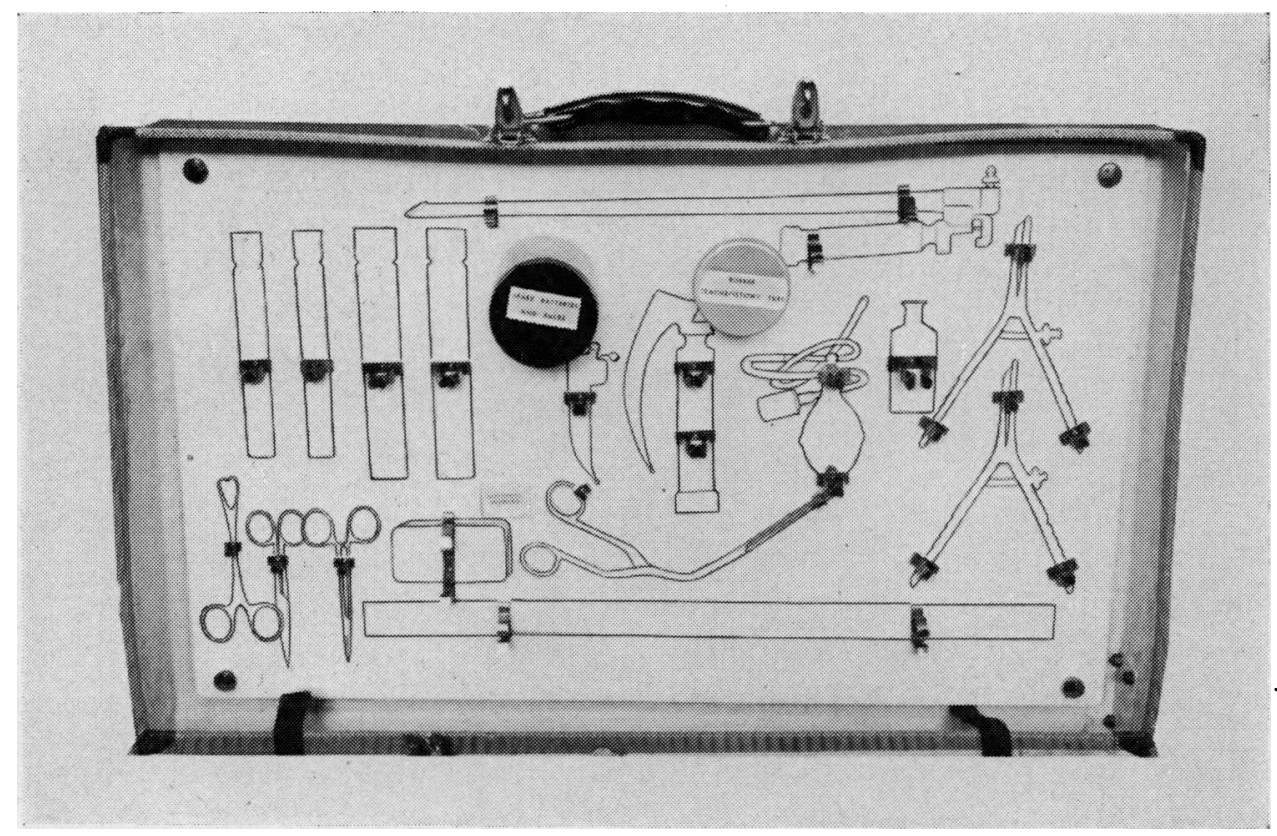

Fig. 1.-The lid showing the diagrams of individual items.

(2) The expanding mechanism fixed in a permanent position, so as to prevent apparatus in the lid damaging the contents of the base.

(3) On the hinge side of the base a steel bar bolted parallel to the upper edge to reinforce the side when the case is open.

(4) A sheet of white painted hardboard with diagrams of the individual items, attached to the lid allows a rapid check that everything is available (see Fig. I).

(5) Transparent plastic luncheon boxes fixed to the base hold other items and drugs (the container for Magill endotracheal tubes was made in the Department's workshop). The labels on the under surface of the box lids, other than the drug box, are small so that their contents can be seen.

(6) Equipment that must be sterilized after use is kept in aluminium containers suitable for autoclaving.

(7) Various sizes of ' Terry clips' maintain the larger items and containers in position, and specially modified clips retain unevenshaped apparatus.

The contents of the suitcase are listed in
Table 2, the base is shown in Fig. 2, and a general view of the equipment in Fig. 3. The size of the underwater-seal drainage bottle precludes its inclusion, but it is kept wrapped in a sterile towel beside the case.

\section{Discussion}

In the absence of a fully-equipped permanent unit to which a severely-ill patient may. be admitted directly this portable equipment has been found to be of value. In the event of an emergency call the suitcase can be collected from a central location, and wheeled immediately to any part of the hospital. No time is wasted in gathering items of equipment required for an individual case, and precious minutes which may be vital for the patient are saved.

Criticism obviously can be levelled at the choice of individual items, but the equipment is intended for use in a busy hospital. The omission of intravenous fluids and a transfusion set was deliberate, as they are always at hand, but modifications could be made profitably under different geographical circumstances. Local flavour favours certain items, for example, the. Oxford inflating 


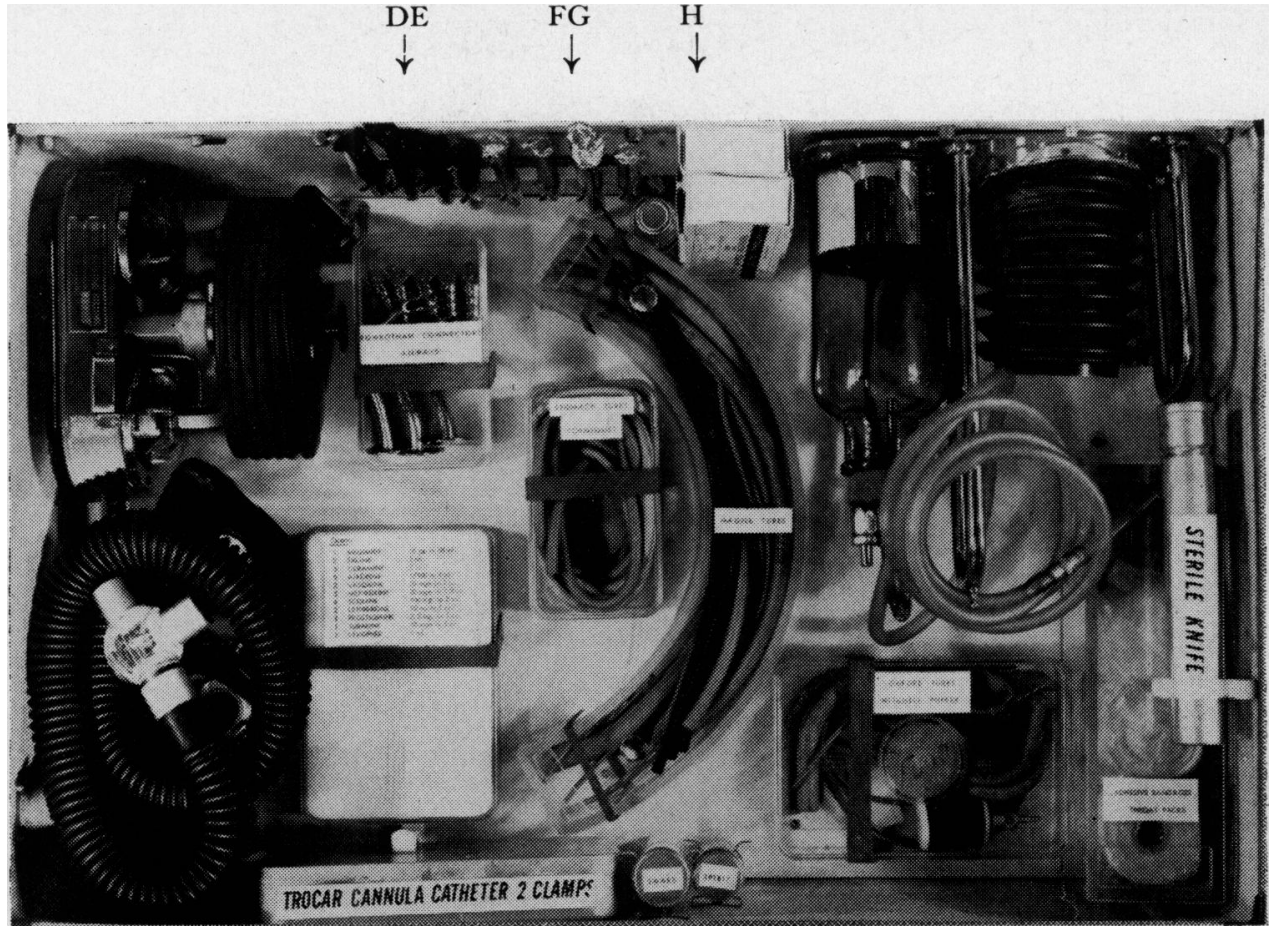

Fig. 2.-The contents of the base.

TABle 2

EQUIPMENT

The Lid: Syringes, $2 \times 2 \mathrm{ml} ., 2 \times 10 \mathrm{ml}$. Spare batteries + bulbs

Tracheostomy tube

Bronchoscope

Fergusson's mouth gag with Acland jaws, $\times 2$

$4 \%$ lignocaine for topical use

Macintosh laryngeal spray

Macintosh laryngoscope

Bryce-Smith infant's straight blade

Mayo tongue forceps

Scissors

Spencer Wells clip

Mitchell intravenous needle $\times 2$

Magill intubating forceps

Suction catheters

The Base: Oxford inflating bellows

Elephant corrugated tubing

Ruben non-return valve

Everseal face masks, sizes $1,2,3$

Catheter mount

Selection of drugs
The Base-cont.:

Drilled Rowbotham connectors $\times 5$

Water's airways $\times 3$

Stomach tube

Rubber tourniquet

Selection of Magill endotracheal tubes

Gum elastic bougies

Trocar, cannula, catheter +2 clamps

Clean cotton wool swabs

Sterile surgical spirit

$1 \%$ lignocaine with 100000 adrenalig for local infiltration

Thiopentone $0.5 \mathrm{gm}, 2$ packs

Ambu suction apparatus

Selection of Oxford non-kinking endor tracheal tubes

Mitchell endotracheal tube cuff inflator (E)

Pharyngeal pack

(N)

Crepe bandage

0

Adhesive strapping

(1)

Hypodermic needles, I drawing up, $3 \times \cdot$ S.W.G., $2 \times 14$ S.W.G., $2 \times 16$ S.W.G 

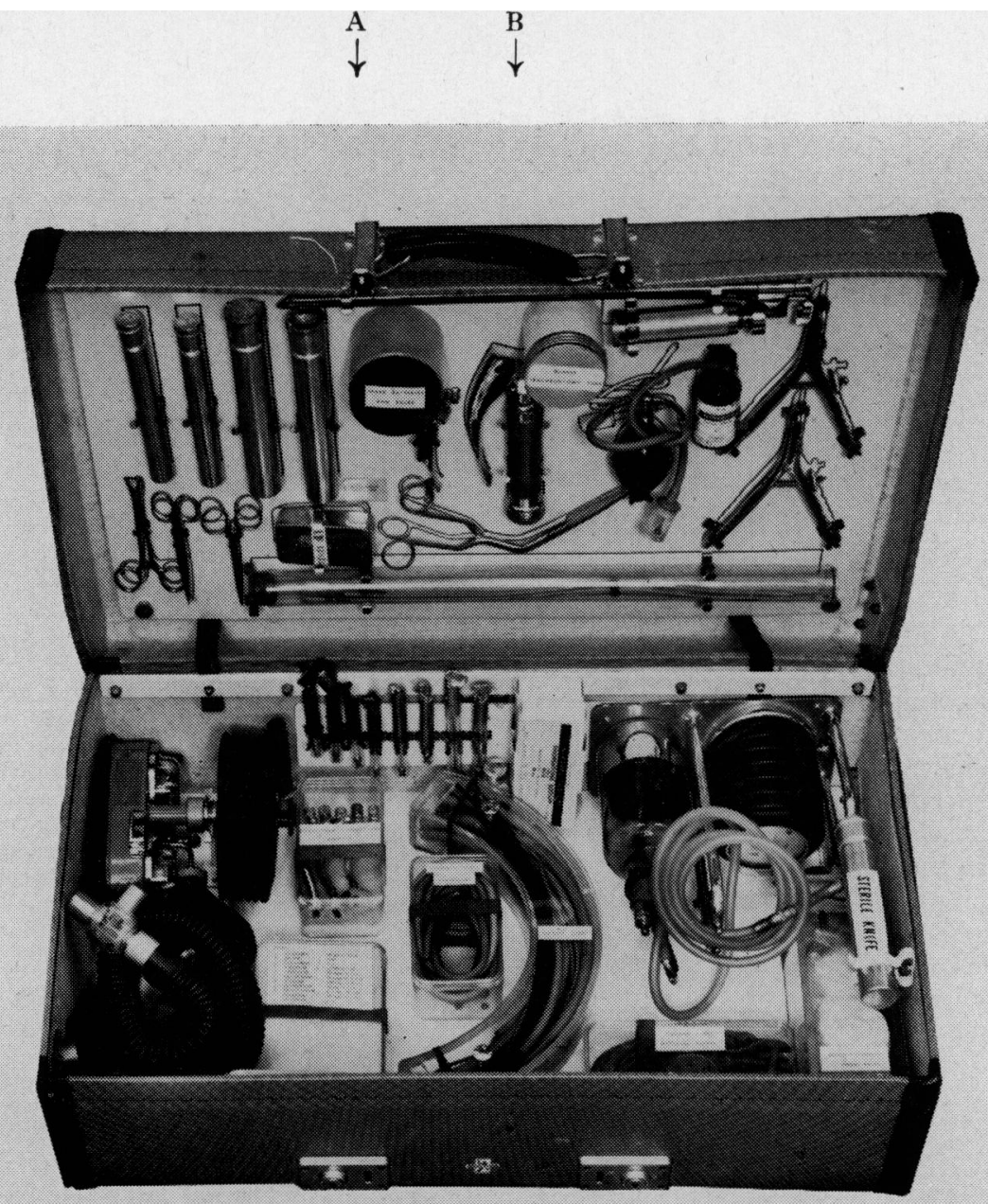

bellows (Macintosh, 1953) is familiar equipment, but an 'Ambu bag' would serve equally well. Both have the merits of simplicity and utilizing air, thus eliminating the need for heavy cylinders.

\section{Summary}

The problem of the expanding role of the anæsthetist in medicine is mentioned, and the principle of intensive therapy considered. Equipment for a portable intensive therapy unit is described, and its use over a ten-month period considered.

We would like to thank Dr. R. Bryce-Smith for assistance with the manuscript, and Mr. R. Corney (Senior Anæsthetic Technician, The Radcliffe Infirmary) for constructional arrangements inside the suitcase.

\section{REFERENCE}

Macintosh, R. R. (1953): Oxford Inflating Bellows, Brit. med. F., ii, 202. 